\title{
Idea Management: A Life-cycle Perspective on Innovation
}

\author{
Håkon Iversen ${ }^{1}$, Kjetil Kristensen ${ }^{2}$, Christine Schei Liland ${ }^{1}$, Thomas Berman ${ }^{1}$, Nina Enger ${ }^{3}$, Tom Losnedahl ${ }^{4}$ \\ ${ }^{1}$ Devoteam daVinci, Hoffsveien 21-23, N-0275 Oslo, Norway, \{hi, csl, tb\}@davinci.no \\ ${ }^{2}$ ESoCE-NET, Via Cortina D’Ampezzo 164,00135 Rome, Italy, kristensen@esoce.net \\ ${ }^{3}$ Human Design Norway, nina.enger@ninaenger.com \\ ${ }^{4}$ Accel, tom.losnedahl@accel.no
}

\begin{abstract}
Innovation is rapidly becoming a strategic priority, but there is a large gap between the perceived importance of innovation and the effectiveness and appropriateness of approaches and methods used to systematically support and accelerate innovation.

This paper presents results and conclusions from a new Idea Management concept that has been developed, introduced and tested in two company-wide idea campaigns in a Norwegian consulting company. This Idea Management concept is based on a life-cycle perspective on innovation, where the aim is to support all phases from insight to post-implementation learning and feedback. The overall concept is described, and comparative analyses of the two idea campaigns and three different Idea Management categories are provided together with conclusions and recommendations for companies interested in improving their Idea Management practices.
\end{abstract}

\section{Keywords}

Idea management, collaborative innovation, knowledge management, idea campaign

\section{Introduction}

There is a growing awareness of the importance of innovation and in many companies innovation is a strategic priority. Organisations in high-tech and knowledge-intensive industries are constantly seeking ideas and concepts that can help them gain a competitive advantage. The percentage of total sales coming from new products rose steadily from 33\% in the period 19761981 to $42 \%$ in the period 1985-1990 [Cooper, 1993]. This trend is continuing. A recent study [Barsh, Capozzi, Davidson, 2007] reports that 70 percent of executives say innovation is among their top three priorities for driving growth, but only 38 percent of top executives report that their organisations encourage learning from failed innovations, a view that is shared by less that 25 percent of lower-rank leaders. 65 percent of senior executives are only "somewhat", "a little" or "not at all" confident about the decisions they make to stimulate innovation [Barsh, Capozzi, Mendonc, 2007]. This indicates a gap between the perceived importance of innovation and the effectiveness and appropriateness of approaches and methods used to systematically support and accelerate innovation.

Innovation is related to putting data, information and knowledge into practice, and there appears to be a strong need for new concepts and instruments that can offer better support and facilitation of innovation processes from the very early stage through implementation and the often overlooked post-implementation learning \& feedback phase. This paper will explore how organizations can use Idea Management to strengthen their innovative capabilities by tapping into the potential of their employees' knowledge and creativity. Logan et. al. [2005] defines idea management as the process of developing, identifying and using valuable insights or alternatives that otherwise would not have emerged through normal processes. For the purpose of this paper, Idea Management is defined as a life-cycle model to systematically generate, capture, develop, 
enrich, evaluate, select and implement ideas that solve specific problems, obtain continuous improvements or achieve groundbreaking innovation.

This paper further describes lessons learned through various campaigns with respect to how an Idea Management concept may work and be implemented in knowledge-based organisations.

\subsection{Collaborative Innovation and Network-based Idea Management}

Knowledge is not passed on from one individual to the next, but co-created on interfaces between people, knowledge areas and disciplines. The common view that strict protection of IPR (Intellectual Property Rights) is the only sustainable way of keeping a competitive advantage is now challenged by alternative, open approaches to sharing knowledge [Chesbrough, 2003]. Whereas many progressive companies today appear to favour open innovation models over closed ones, a recent HBR article [Pisano and Verganti, 2008] argues that singular approaches may not work equally well in all contexts. This has implications for how collaboration should be organized and managed, depending on the desired characteristics of the solution(s) and IPR requirements.

In a 2006 study of 765 C-level executives, IBM [2006] found that collaboration is considered very important for achieving innovation by over 75 percent of the respondents. The same study demonstrates that only slightly more than 50 percent responded that they collaborate to the extent that is required to reap the potential benefits. The most important sources of ideas have been identified as employees (41 percent), business partners and customers (more than 35 percent each), consultants and competitors (more than 20 percent each), while internal sales and service units and internal R\&D count for less than 20 percent each [IBM, 2006, respondents could select up to three choices]. Given this overall picture, it appears that innovation and idea collection are highly networked and collaborative activities, and therefore, an appropriate Idea Management approach must accommodate and promote interaction between stakeholders to be effective. The experiences we gained when implementing our Idea Management concept, support this assertion.

Furthermore, it is our hypothesis that most individuals will naturally provide ideas that can be categorized as improvements rather than true innovations. Unless continuously guided and triggered in a collaborative environment, we believe that it is difficult for individuals to get beyond the obvious and readily available ideas.

\subsection{Research Questions}

- Collaborative innovation culture: What are the key characteristics of innovative business cultures?

- Insight and innovation flow stage enablers: What is the significance of domain-specific insight prior to launching the campaign? What triggers an individual to open up and share their ideas? How can the innovation flow stage be managed and sustained?

- Collaborative innovation tools: What kind of tools and tool categories exists that can enable, support and stimulate collaborative innovation?

These research questions have been formulated based on the belief that employees in any company have the competence and insight as well as ideas on how to develop their organization.

\section{Method}

This paper documents the results of two idea campaigns carried out in Devoteam daVinci, a Norwegian consulting company with approximately 100 employees. The company has been running idea campaigns based on the Idea Management concept described in this paper since Q4, 2008 , with the purpose of radically increasing the number of commercially exploitable ideas and to improve the innovation capabilities of the company. 
Implementing Idea Management in organizations is not a one-time, stand-alone event. Devoteam daVinci implemented the Idea Management concept on a test and trial basis and it is evident that the term "Practice makes perfect" is highly applicable for both employees, managers and facilitators. The implementation process is illustrated in figure 1 and briefly described below:

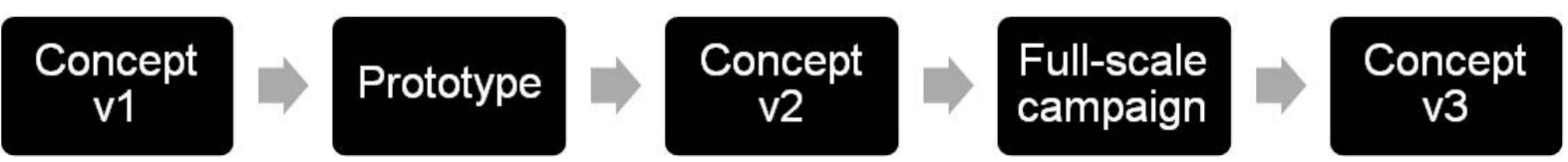

Figure 1: Idea Management implementation process

1. An initial Idea Management concept was developed, including cultural prerequisites, a proposed process and tool requirements.

2. A prototype for both the Idea Management process and supporting tools was launched in the organization to gain experience.

3. The Idea Management concept was revised based on the results and an evaluation of the first prototype campaign.

4. The first full-scale Idea Management campaign was launched.

5. A second revision of the concept was done to further improve our ability to conduct future idea campaigns.

A very simple Idea Management system, covering only selected parts of the specification, was deliberately used to focus on the processes and the overall Idea Management concept rather than the technical peculiarities of the chosen system.

Our initial Idea Management concept proved to be robust and only minor adjustments and detailing were needed after the first campaigns. However, we believe that both the concept itself and the implementation process should allow for necessary adjustments as well as a pilot period to ensure a suitable and practical adaptation to the company seeking to introduce any Idea Management concept.

\section{The Idea Management Concept}

The Idea Management concept version 3 is visualized in figure 2:

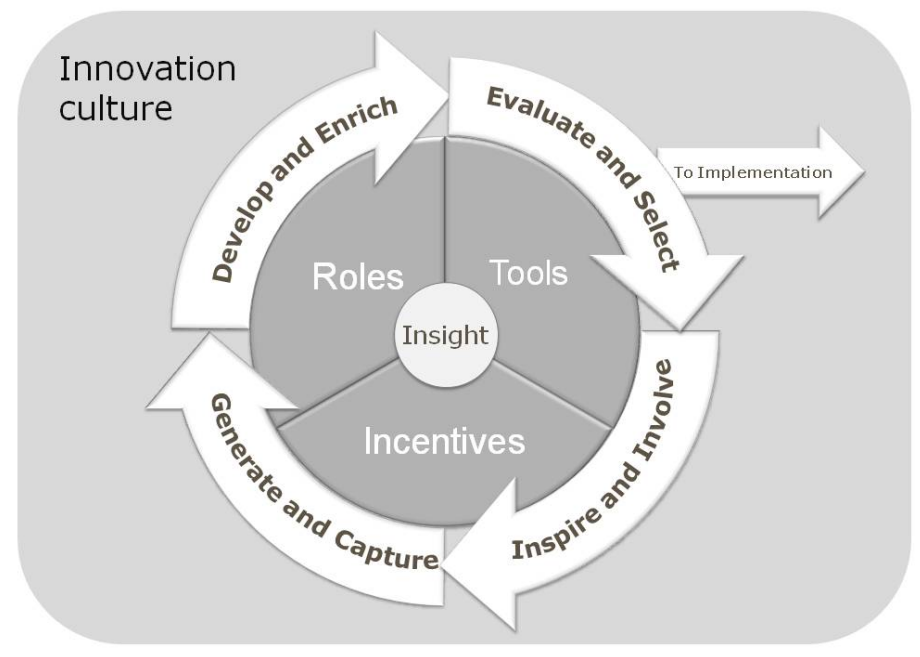

Figure 2: Devoteam daVinci Idea Management concept

The concept is based on an iterative phase model in which each phase has its own characteristics. Appropriate triggers, roles, incentives and tools must be defined and implemented before idea 
campaigns are launched. To succeed with an idea campaign it is essential to have a dedicated management team and a cultural climate which supports and promotes innovation.

Furthermore, it is our experience that the phase characteristics and the required triggers will differ depending on whether the main objective for the campaign is problem-solving, continuous improvement or groundbreaking innovation. This last realization came as a direct result of our chosen path of "trial and error", as we were not fully aware of this dimension when we started our process. The aim for the campaign must be clearly communicated in the first phase: "Inspire and Involve", allowing for the use of appropriate triggers and tools throughout the campaign. An overview of the different approaches for these three categories is provided in table 1.

\begin{tabular}{|c|c|c|c|}
\hline Phase & PROBLEM-SOLVING & $\begin{array}{l}\text { CONTINUOUS } \\
\text { IMPROVEMENT }\end{array}$ & $\begin{array}{l}\text { GROUNDBREAKING } \\
\text { INNOVATION }\end{array}$ \\
\hline $\begin{array}{l}\text { Inspire and } \\
\text { Involve }\end{array}$ & $\begin{array}{l}\text { - Involves a defined group } \\
\text { of people within and, if } \\
\text { appropriate, outside the } \\
\text { org. during a limited } \\
\text { time frame } \\
\text { - Define and present a } \\
\text { specific problem } \\
\text { - Distribute background } \\
\text { information (incl. how } \\
\text { other industries have } \\
\text { solved similar problems) }\end{array}$ & $\begin{array}{ll}\text { - All employees are } \\
\text { involved in a continuous } \\
\text { improvement process } \\
\text { - Idea manager produces } \\
\text { monthly updates } \\
\text { (triggers) that build } \\
\text { insight in accordance } \\
\text { with company strategy } \\
\text { - Background information } \\
\text { (incl. how other } \\
\text { industries have solved } \\
\text { similar problems) is } \\
\text { posted / distributed at } \\
\text { regular intervals } \\
\text { - Half-yearly ceremonies } \\
\text { for top ideas and idea } \\
\text { owners appraisal }\end{array}$ & $\begin{array}{l}\text { - Gather insight about } \\
\text { customers' behaviour } \\
\text { and needs (i.e. by } \\
\text { conducting } \\
\text { ethnographic studies) } \\
\text { - Gather background } \\
\text { information (incl. how } \\
\text { other industries have } \\
\text { solved similar } \\
\text { problems) } \\
\text { - Distribute insight to } \\
\text { team of } \\
\text { employees/partners } \\
\text { - Make sure team has } \\
\text { sufficient mandate }\end{array}$ \\
\hline $\begin{array}{l}\text { Generate and } \\
\text { Capture }\end{array}$ & $\begin{array}{l}\text { Brainstorming activities } \\
\text { and individual idea } \\
\text { generation }\end{array}$ & 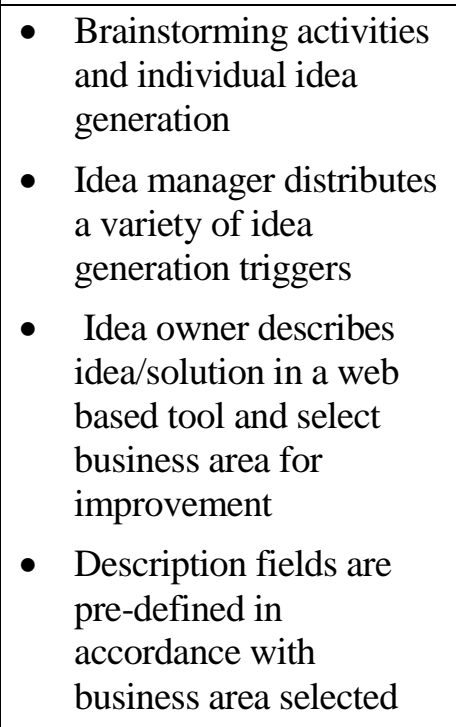 & 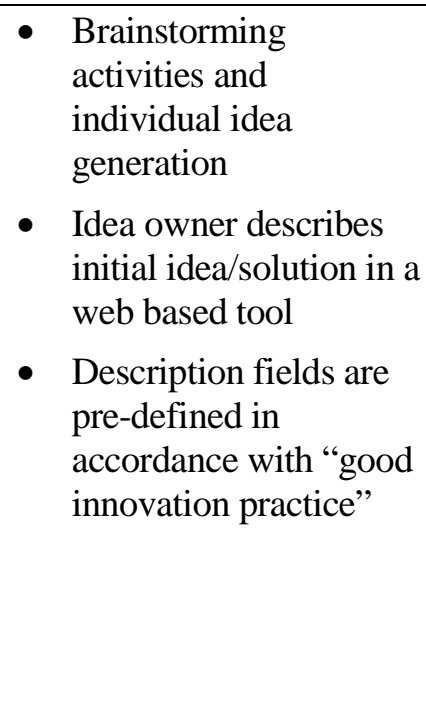 \\
\hline $\begin{array}{l}\text { Develop and } \\
\text { Enrich }\end{array}$ & $\begin{array}{l}\text { Collective development } \\
\text { by adding comments, } \\
\text { pictures, links etc. in } \\
\text { web tool } \\
\text { Idea manager has an } \\
\text { active role in facilitating } \\
\text { idea development, } \\
\text { including merging }\end{array}$ & $\begin{array}{l}\text { Collective development } \\
\text { by all employees (adding } \\
\text { comments, pictures, } \\
\text { links etc. in web tool) } \\
\text { Idea manager has an } \\
\text { active role in facilitating } \\
\text { idea development, } \\
\text { including merging }\end{array}$ & 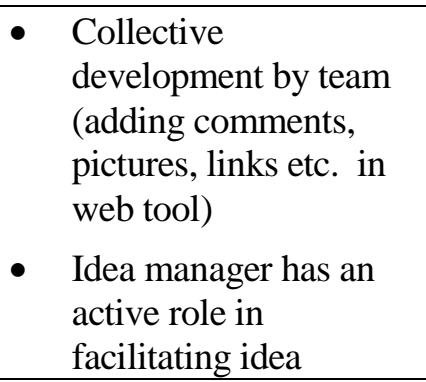 \\
\hline
\end{tabular}




\begin{tabular}{|c|c|c|c|}
\hline Phase & PROBLEM-SOLVING & $\begin{array}{l}\text { CONTINUOUS } \\
\text { IMPROVEMENT }\end{array}$ & $\begin{array}{l}\text { GROUNDBREAKING } \\
\text { INNOVATION }\end{array}$ \\
\hline & $\begin{array}{l}\text { similar ideas } \\
\text { - Interesting ideas that } \\
\text { need further enrichment } \\
\text { are selected for } \\
\text { prototyping, } \\
\text { visualisation and, if } \\
\text { appropriate, business } \\
\text { plan "light" before final } \\
\text { evaluation/selection }\end{array}$ & $\begin{array}{l}\text { similar ideas } \\
\text { - Interesting ideas that } \\
\text { need further enrichment } \\
\text { are selected for } \\
\text { prototyping, } \\
\text { visualisation and, if } \\
\text { appropriate, business } \\
\text { plan "light" before final } \\
\text { evaluation/selection }\end{array}$ & $\begin{array}{l}\text { development, including } \\
\text { merging similar ideas } \\
\text { - Team selects ideas that } \\
\text { they believe in and } \\
\text { creates prototypes and } \\
\text { visualisations of these } \\
\text { - Team creates business } \\
\text { plan "light" }\end{array}$ \\
\hline $\begin{array}{l}\text { Evaluation } \\
\text { and Selection }\end{array}$ & 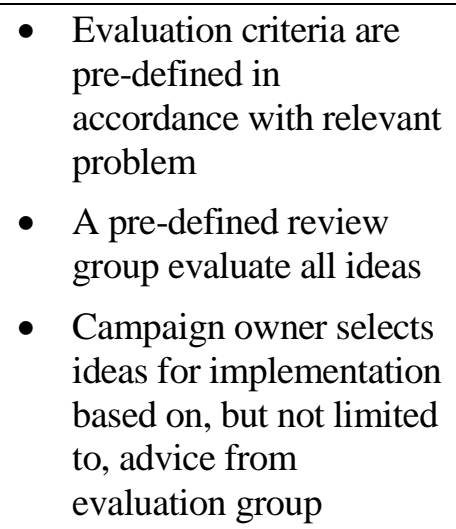 & $\begin{array}{l}\text { - } \begin{array}{l}\text { Ideas are evaluated by } \\
\text { business area manager }\end{array} \\
\text { - } \quad \text { Evaluation criteria are } \\
\text { pre-defined in } \\
\text { accordance with relevant } \\
\text { improvement areas } \\
\text { - } \quad \begin{array}{l}\text { Business area manager } \\
\text { selects ideas for } \\
\text { implementation }\end{array}\end{array}$ & $\begin{array}{l}\text { - Ideas are evaluated by } \\
\text { Innovation Board } \\
\text { (Executive) based on } \\
\text { strategic fit, belief in } \\
\text { idea team, market } \\
\text { potential etc.) } \\
\text { - Ideas are selected by } \\
\text { Innovation Board } \\
\text { (Executive) }\end{array}$ \\
\hline $\begin{array}{l}\text { Implement- } \\
\text { ation }\end{array}$ & $\begin{array}{l}\text { Campaign owner is } \\
\text { responsible for } \\
\text { implementation of } \\
\text { selected ideas }\end{array}$ & $\begin{array}{l}\text { Business area manager is } \\
\text { responsible for } \\
\text { implementation of } \\
\text { selected ideas relevant to } \\
\text { particular business area }\end{array}$ & $\begin{array}{l}\text { Innovation Board is } \\
\text { responsible for } \\
\text { implementing selected } \\
\text { ideas, but Idea team } \\
\text { should be included }\end{array}$ \\
\hline $\begin{array}{l}\text { Post- } \\
\text { Implement- } \\
\text { ation } \\
\text { Learning \& } \\
\text { feedback }\end{array}$ & $\begin{array}{ll}\text { - } & \text { Idea manager conducts a } \\
\text { user survey after } \\
\text { campaign completion } \\
\text { - } \\
\text { Idea manager conducts } \\
\text { interviews with selected } \\
\text { idea owners, review } \\
\text { group and campaign } \\
\text { owner } \\
\text { - Idea manager produces a } \\
\text { "Lessons learned" report } \\
\text { - Idea manager adjusts } \\
\text { process according to } \\
\text { feedback }\end{array}$ & $\begin{array}{l}\text { - Idea manager conducts a } \\
\text { quarterly user survey } \\
\text { - Idea manager conducts } \\
\text { quarterly interviews with } \\
\text { selected idea owners and } \\
\text { business area Managers } \\
\text { - Idea manager produces } \\
\text { quarterly "Lessons } \\
\text { learned" report } \\
\text { - Idea manager adjusts } \\
\text { process quarterly } \\
\text { according to feedback }\end{array}$ & $\begin{array}{l}\text { - Idea manager conducts } \\
\text { quarterly interviews } \\
\text { with selected idea } \\
\text { owners and Innovation } \\
\text { Board } \\
\text { - } \text { Idea manager produces } \\
\text { half yearly "Lessons } \\
\text { learned" report } \\
\text { - Idea manager adjusts } \\
\text { process quarterly } \\
\text { according to feedback }\end{array}$ \\
\hline
\end{tabular}

Table 1: Overview - Different Idea Management approaches according to desired outcome

\section{Campaign Results}

Our main purpose of running the first two idea campaigns was to provide the concept development team with feedback on the suitability and quality of the developed concept. However, it quickly became evident that the campaigns had an intrinsic value in that they provided an arena and instruments for tapping into the collective insights and ideas of the employees with respect to identified problem areas. That which was only meant as a prototype and pilot, established itself immediately as a "live" and productive process in the company.

A summary of results from the two initial campaigns is provided in Table 2. 


\begin{tabular}{|l|l|l|}
\hline Item & Campaign 1 & Campaign 2 \\
\hline Purpose of campaign & $\begin{array}{l}\text { How to furnish our new } \\
\text { offices to support } \\
\text { collaboration, innovation, a } \\
\text { good working environment } \\
\text { and environmental profile. }\end{array}$ & $\begin{array}{l}\text { How to ensure that all } \\
\text { employees are fully utilized in } \\
\text { the first half of 2009. }\end{array}$ \\
\hline Approach & Problem-solving & Problem-solving \\
\hline Invited participants & 95 (all employees) & 95 (all employees) \\
\hline Participants who logged in & $57 \%$ (of all employees) & $79 \%$ (of all employees) \\
\hline Participants who contributed & $41 \%$ (of all employees) & $47 \%$ (of all employees) \\
\hline Time period for campaign & 2 weeks & 2 weeks \\
\hline Launch information & $\begin{array}{l}\text { General meeting and } \\
\text { introductory email from CEO }\end{array}$ & $\begin{array}{l}\text { Several emails from CEO, } \\
\text { campaign owner and }\end{array}$ \\
\hline innovation manager
\end{tabular}

Table 2: Facts and statistics from the two completed idea campaigns

\section{Findings}

Main findings from the evaluation of the two completed Idea Management campaigns in Devoteam daVinci are summarized below.

\subsection{Collaborative Innovation Culture}

None of the ideas captured in the performed campaigns in Devoteam daVinci can be characterized as radical innovations. Even if not intentionally, more or less all of them belonged to the 'continuous improvement' category, thereby supporting our hypothesis regarding people's natural tendency to seek improvements rather than ground-breaking innovation. It could be argued that the challenges posed were not phrased to encourage radical innovation and that prototyping and visualisation exercises were not sufficiently promoted. These are all elements that we have found necessary to allow for any inherent radical innovation to emerge. Inherent 
radical innovation is not necessarily apparent in an idea, but must be allowed to evolve through collaborative activity.

Our conclusion is that if the main objective for a campaign is groundbreaking innovation, this must be clearly communicated when launching the campaign, and efforts must be made to uncovering and facilitating the elements that stimulate individuals, groups and organizations to innovate. Regardless of the degree of innovation that is sought, clearly defined key roles for the idea campaign must be established:

- Innovation Manager: Responsible for innovation as a whole in the company

- Campaign Owner: Responsible for the campaign

- Review Group: Selected persons that on behalf of the Campaign Owner are to review and nominate incoming ideas

\subsection{Insight and Innovation Flow Stage Enablers}

Good ideas do not emerge by themselves. Insight into the relevant challenge is required in order to develop good and novel ideas. Our experience stresses the importance of sufficient insight into a given problem, as well as a clear description of the challenge at hand, prior to the launch of a campaign, i.e. in the "Inspire and Involve" phase.

As shown in table 1, the second completed idea campaign generated more ideas than the first. The threshold for individuals to open up and share their ideas was low and based on feedback from participants we have concluded that reasons for this include:

- The campaign was considered important by the employees

- The campaign was well prepared and well communicated

- Influential persons in the company posted the first few ideas.

- Employees felt safe when sharing ideas and were not afraid of being stigmatised for coming up with "strange" proposals

- Employees had gained a better understanding of both the process and expectations after the first campaign

Ethnographic studies could be used to dive deeper into the behaviour of the idea campaign participants but were not conducted as part of the implementation process.

Ideas to be selected for implementation need to be sufficiently described. Our experience shows that the initial idea description made by the idea owner in the "Generate and Capture" phase is seldom complete. Several iterations in the enrichment phase are needed, where tools and methods to further the cultivation of ideas should be utilized, including visualisation and prototyping, to enhance the quality of any campaign. Each iteration should have a clear mandate, start and end times, and should be managed and controlled strictly according to this. The mandate for the next iteration should be revised on the basis of the results from the previous one.

\subsection{Collaborative Innovation Tools}

Available Idea Management systems tend to focus on the ability to capture and share a large number of ideas on minor issues and to review and rate those ideas. Less focus is given to the generation and capturing of more groundbreaking ideas, scrutinizing, developing, visualizing and enriching ideas and issues in collaboration, in order to make the ones with the greatest potential ready for implementation as well as learning from implementation experiences.

The performed idea campaigns clearly revealed that each phase in the Idea Management lifecycle model needs to be treated separately, as their characteristics require different thinking and communication approaches as well as, in many cases, different tools and systems. 
We are of the opinion that, as of today, no commercially available Idea Management system fully supports innovation and collaboration across all Idea Management life-cycle phases. Furthermore, the support that is offered does not satisfy our requirements pertaining to the cultural aspects of collaborative innovation. Social networking software, which is considered to be a key enabler of novel innovation chains and networks, has not been well integrated in available Idea Management systems. Suppliers of Idea Management systems seem largely to be unaware of these implications and our view is that most have a somewhat simplified understanding of what Idea Management really is and can become. The approach to both process support and user interaction in available Idea Management tools is, in our opinion, somewhat old-fashioned and does not take into consideration the multiple forms and arenas in which collaboration occurs. This can to some extent explain why Idea Management tools have a market penetration of less than 1 percent of the target audience, as reported by Logan et. al. [2005].

\section{Conclusions}

A successful Idea Management implementation is hard work, and requires continuous attention and an ability to quickly adjust defined processes based on experience gained. A clear understanding of the challenges at hand and the desired outcome of any idea campaign is imperative if a company is to utilize Idea Management as a tool for problem-solving, continuous improvement or groundbreaking innovation. Furthermore, a business culture that relies solely on the individual's ability to generate and develop innovative ideas without actively promoting and facilitating collaboration has a significantly reduced chance of achieving its goal. We have found that Idea Management tools are of less importance to the process than first imagined, at least as long as available tools do not sufficiently support collaboration across different phases and have not taken into consideration the aspect of social networking. Finally, lessons learned from the two campaigns demonstrate that a proper implementation of the described Idea Management concept will greatly aid any business seeking to systematically support and accelerate innovation, both within the business as well as in collaboration with external stakeholders.

\section{Acknowledgements}

This work has been co-funded by Devoteam daVinci, ESoCE-NET, Kristensen Consulting, and the ECOSPACE Integrated Project. ECOSPACE is co-funded by the European Commission under the IST Priority within the 6th Framework Programme. The authors wish to acknowledge the Commission for their support.

\section{References}

Barsh, Capozzi, Davidson. Leadership and Innovation. McKinsey Quarterly, Number 1, 2008

Barsh, Capozzi, Mendonca. How companies approach innovation: A McKinsey Global Survey. McKinsey Quarterly, October 2007.

Cooper Robert G.: Winning at New Products. Accelerating the Process from Idea to Launch. Addison-Wesley, Reading, 1993.

Chesbrough, H.: Open Innovation. The New Imperative for Creating and Profiting from Technology. Harvard Business School Press, 2003.

IBM: Expanding the Innovation Horizon. The Global CEO Study 2006, IBM Global Business Services. IBM, 2006.

Logan Debra, Knox Rita E., Andrews Whit et. al.: Hype Cycle for the High-Performance Workplace. Gartner Research Report, Gartner Research, 2005.

Pisano Gary P., Verganti Roberto: Which Kind of Collaboration is Right for You? Harvard Business Review. December edition, 2008. 